\title{
Meta
}

Journal des traducteurs

Translators' Journal

\section{Translating Computer Abbreviations from English into Spanish: Main Types and Problems}

\section{José R. Belda Medina}

Volume 49, numéro 4, décembre 2004

URI : https://id.erudit.org/iderudit/009790ar

DOI : https://doi.org/10.7202/009790ar

Aller au sommaire du numéro

Éditeur(s)

Les Presses de l'Université de Montréal

ISSN

0026-0452 (imprimé)

1492-1421 (numérique)

Découvrir la revue

Citer cet article

Belda Medina, J. R. (2004). Translating Computer Abbreviations from English into Spanish: Main Types and Problems. Meta, 49(4), 920-929.

https://doi.org/10.7202/009790ar

\section{Résumé de l'article}

L'espagnol a accueilli dernièrement une pléthore de termes informatiques provenant de l'anglais. Certains ont été acceptés sans aucune modification. Le nombre de termes informatiques anglais que l'on emploie en espagnol augmente constamment. Certains termes sont établis depuis longtemps, par exemple, RAM, ROM et PC, mais d'autres viennent d'apparaître, comme WWW, ISP, IRC et HTML. Le but de cet article est de classifier les abréviations anglaises les plus souvent utilisées dans la terminologie de l'informatique et d'identifier les problèmes les plus importants que l'on trouve dans la traduction de ces abréviations vers l'espagnol, en donnant aussi quelques solutions. 


\title{
ÉTUDES TERMINOLOGIQUES ET LINGUISTIQUES
}

\section{Translating Computer Abbreviations from English into Spanish: Main Types and Problems}

\author{
JOSÉ R. BELDA MEDINA \\ University of Alicante, Alicante, Spain \\ jr.belda@ua.es
}

\begin{abstract}
RÉSUMÉ
L'espagnol a accueilli dernièrement une pléthore de termes informatiques provenant de l'anglais. Certains ont été acceptés sans aucune modification. Le nombre de termes informatiques anglais que l'on emploie en espagnol augmente constamment. Certains termes sont établis depuis longtemps, par exemple, RAM, ROM et PC, mais d'autres viennent d'apparaître, comme WWW, ISP, IRC et HTML. Le but de cet article est de classifier les abréviations anglaises les plus souvent utilisées dans la terminologie de l'informatique et d'identifier les problèmes les plus importants que l'on trouve dans la traduction de ces abréviations vers l'espagnol, en donnant aussi quelques solutions.
\end{abstract}

\begin{abstract}
Many computer terms have entered the Spanish language in recent years. Some of them are widely adopted without any previous modification. The number of English computer abbreviations used in Spanish is constantly increasing. Some of them are well-established, e.g. RAM, ROM, PC, but others have appeared very recently, e.g. WWW, ISP, IRC, HTML. This paper is intended to classify the different types of English abbreviations most commonly used in computer terminology and to identify the most important problems for their translation into Spanish as well as provide some solutions for it.
\end{abstract}

\section{MOTS-CLÉS/KEYWORDS}

abbreviations, classification, computer terminology, translation problems, Spanish

\section{Introduction}

Abbreviations have been on the increase in all fields of the English vocabulary in recent times, as attested by Adams (1973) and Bauer (1983). This is also the case of the Spanish language, an aspect pointed out by Lang (1990) and Rodríguez (1987, $1989,1990,1991,1993)$ among others. However, the origins of this lexical process of abbreviating a word into a series of initials has a long history, which has been described by Rodríguez (1980, 1984), Cannon (1987, 1989, 1993), Petrucci (1989) and Cannon and Rodríguez (1994).

Computer terminology has recently become the focus of several studies in the fields of Translation Studies and English for Specific Purposes or IPA in Spanish, as described by Alcaraz (2000). This vocabulary is constantly changing, and it is partly due to the high amount of abbreviations making part of it, as can be seen in some 
dictionaries and glossaries like Vaquero Sánchez (1993) and Collins (1997). Most of these abbreviated forms are originally coined in English and have entered the Spanish language with their original spelling: PC, RAM, WWW, URL, CD-ROM, POP3, etc.

The influence of English computer abbreviations on Spanish has been addressed by authors such as Bocanegra (1999) and Linder (1999). One of the major problems for translators is how to deal with all these abbreviations since English is often the source language and these forms are frequently adopted into Spanish without any previous modification. As a result, very few of these terms have a corresponding abbreviated form that is widely known and accepted among computer users and professionals in Spanish. A few exceptions are 'I/O' (from Input/Output), 'ISP' (from Internet Service Provider) and 'ISDN' (from Integrated Services Digital Network) in English, which correspond respectively to 'E/S' (from Entrada/Salida), 'PSI' (from Proveedor de Servicios para Internet) and 'RDSI' (from Red Digital de Servicios Integrados) in Spanish.

However, as the pioneering work of Aguado de Cea (1993) tried to demonstrate, the most common practice in Spanish is either using the original English form preceded by the definite or indefinite article, e.g. 'un CD-ROM,' or expanding the full term corresponding to the last English initial, e.g. 'memoria RAM,' where 'memoria' and $M$ have exactly the same meaning. In fact, Barry (1991) also provides some examples for the latter case in English, such as 'RAM memory.' Therefore, most computer users in Spanish know what 'PC' or 'CD-ROM' are, but they are unable to tell the origin of each English initial.

There have been recent attempts to translate some of these abbreviations and even adopt a corresponding Spanish abbreviated form, but generally they have been unsuccessful, for example 'WWW' (from World Wide Web) in English and 'MMM' (from Malla Máxima Mundial) in Spanish, which was proposed by the CVC or Centro Virtual Cervantes. These proposals are often ignored or neglected by today's professionals as it was the case of other previous abbreviations such as 'dibín' (from dígito binario), recommended some years ago by the Diccionario de la Real Academia as a suitable translation for 'bit' (from binary digit) in English.

On the whole, there is great confusion about how to translate computer abbreviations into Spanish. In this article we intend to establish the two main types of English computer abbreviations that are currently used and provide some solutions for their adequate translation into Spanish.

\section{Main types of computer abbreviations}

In general terms, we can distinguish four main types of abbreviations from a morphological point of view: ${ }^{1}$ simple abbreviations, clipped words, blends and complex abbreviations. Simple abbreviations are those formed by taking just the initial or any other letter from a group of words, e.g. 'ROM' (from Read-Only Memory). They are here called simple abbreviations because they take a single initial from each word, except for certain compounds including a classical element, that may take two letters from the same word, e.g. 'MB' (from MegaByte) and 'HT' (from HyperText). ${ }^{2}$ A clipped word is the result of clipping a full word while maintaining three or more contiguous letters from the same word in the abbreviated form, e.g. 'tab' (from tabulate) and 'del' (from delete). Blends are compound words resulting from putting 
together two words that have been previously clipped or abbreviated, such as 'modem' (from modulator-demodulator). Finally, complex abbreviations are those combining frequently two or more simple abbreviations through several typographic symbols, such as the hyphen, e.g. 'CD-ROM', 'MS-DOS', or the slash, e.g. 'TCP/IP'.

Our focus here will be on simple abbreviations, as they are the most common ones, as well as on their translation into Spanish. We may distinguish several types within this group, depending on the number of initials included in the final abbreviated form: two, three, four and five or more initials. Some popular examples of simple abbreviations formed by two initials are 'CD' (from Compact Disk), 'PC' (from Personal Computer) and 'IP' (from Internet Protocol). Abbreviations of five or more initials are not very common in computer terminology since their long structure might contravene the principles of brevity and conciseness that are the basis of this lexical resource, known as abbreviation. Among the scarce examples of simple abbreviations formed by five or more initials we find 'YAHOO' (from Yet Another Hierarchically Officious Oracle), 'WYSIWYG' (from What You See is What You Get) and 'VERONICA' (from Very Easy Rodent Oriented Net-wide Index to Computerized Archives). As can be clearly seen, some of these long abbreviations are shapeintended, e.g. 'VERONICA' and 'YAHOO'.

But the most common simple abbreviations in computer terminology are the ones formed by three and four initials. They also give rise to more errors concerning their translation in Spanish. Therefore, we will concentrate on them in the rest of this paper. Some examples of three-initial abbreviations are 'RAM', 'ROM', 'LCD', 'CRT', 'ISP', 'IRC', 'URL', etc and among four-initial abbreviations we find 'ADSL', 'HTTP', 'HTML', 'ISDN', 'MPEG', etc. The translation of all these forms into Spanish raises two main problems: firstly, maintaining in Spanish the original connection between all the elements combined in the English abbreviation so that the translated and the original versions have exactly the same meaning; secondly, selecting the adequate preposition in Spanish that will link all the elements making part of the abbreviated form. Both problems will be analyzed in detail below.

\section{Three-initial abbreviations}

Among this type of computer abbreviations, two are the most common ones in English.

\subsection{Three-initial abbreviations formed by three nouns}

Several types can be established depending on the grammatical category, the elements included in each abbreviation belong to, i.e., nouns, adjectives, verbs, etc. Thus, the most common type of three-initial abbreviation is the one formed by three consecutive nouns, e.g. 'ISP' (from Internet Service Provider). The first two English nouns work as adjectives, being subordinated to the last noun, 'provider.' The flexibility that allows the English language to convert nouns into adjectives just by placing them before another noun is almost unknown in Spanish. So, this tendency towards conversion or zero-derivation, as this process was called by authors like Adams (1973) and Bauer (1983), can be solved in Spanish by introducing linking elements, mostly prepositions, as in 'proveedor de servicios para Internet,' corresponding to 'Internet 
Service Provider.' Otherwise, the structure in Spanish would be agrammatical and meaningless: 'proveedor servicios Internet.' There are many examples of three-initial abbreviations formed by three consecutive nouns: 'API' (from Application Program Interface), 'BBS' (from Bulletin Board System), 'CRT' (from Cathode Ray Tube), 'GIF' (from Graphics Interchange Format), 'IRC' (from Internet Relay Chat), etc.

The first problem appears when translating into Spanish each term contained in the English abbreviation and trying to maintain the original connection between all the elements so that the original meaning is not altered. In this respect, it is very useful to adopt a formula in order to translate not only this one but also other types of abbreviations. Each formula can represent different types of computer abbreviations. In this case, the structure of three-initial abbreviations that are formed by three consecutive nouns can be represented as follows:

FIGURE 1

\begin{tabular}{|c|c|}
\hline English & Spanish \\
\hline $\operatorname{noun}(3)+\operatorname{noun}(2)+\operatorname{noun}(1)$ & Noun $(1)+$ prep. + noun $(2)+$ prep. + noun $(3)$ \\
\hline$+\mathrm{B}+\mathrm{C}$ & + \\
\hline
\end{tabular}

Spanish needs to invert the order of the different elements combined in this type of abbreviation, so that $\mathrm{A}+\mathrm{B}+\mathrm{C}$ in English becomes $\mathrm{C}+\mathrm{B}+\mathrm{A}$ in the Spanish version. Generally, the first noun modifies the second one and the second noun in turn modifies the third one. Consequently, the formula representing this structure would be $((A)+B)+C$, thus indicating that the first and second nouns are subordinated to the third one in the English abbreviation. We have to take this structure into account in our Spanish translation if we want to preserve the original meaning of the English abbreviation. Otherwise, we are bound to make such mistakes as translating 'CRT' by 'tubo catódico de rayos. 'CRT' stands for 'Cathode Ray Tube' in English, corresponding to 'Tubo de rayos de cátodo' or also to 'Tubo de rayos catódicos' in Spanish. However, the formula we have provided in Figure $1, \mathrm{~A}+\mathrm{B}+\mathrm{C}=\mathrm{C}+\mathrm{B}+\mathrm{A}$, is sometimes altered into $\mathrm{A}+\mathrm{B}+\mathrm{C}=\mathrm{C}+\mathrm{A}+\mathrm{B}$, as in 'Tubo catódico de rayos' or also as in 'Tubo de rayos catódico's, which in English corresponds to 'Ray Cathode Tube' and not to 'Cathode Ray Tube.'

The second main problem in the translation of three-initial abbreviations is deciding what Spanish preposition fits best in each example since these linking elements are not explicit in the original English structure. The preposition depends on each specific case as can be inferred from examples like 'ISP' (from Internet Service Provider), that can be translated as 'Provedor de Servicios para Internet' in Spanish. Here the first preposition is 'de,' indicating 'kind, type,' and the second one is 'para', thus denoting 'use, finality.'

However, the linking element is sometimes omitted when the English abbreviation is translated into Spanish and this can be misleading as it may convey a very different meaning. This fact can be observed in the following two examples: 'ISP' and 'IRC.' The first one, 'ISP', stands for 'Internet Service Provider' in English and is usually translated into Spanish as 'Proveedor de Servicios Internet,' without including any preposition between the second and third nouns, for example by Fernández Calvo (1999). In this case, the Spanish version seems to indicate that 'ISP' is a protocol for 
a service or group of services called Internet rather than specifying that it is a protocol for certain services being offered through the Internet. Internet is not senso strictu a service but an international computer network providing several services to its users such as electronic mail, web searching, real on-time chat, etc. So, the omission of the second preposition in Spanish can be confusing if the user does not know the original meaning in English.

This error appears again in 'IRC' (from Internet Relay Chat), frequently translated in Spanish as 'charla interactiva Internet,' for example in Fernández Calvo (1999) and in Telefónica (1998). This Spanish version would correspond in English to 'Internet interactive chat.' But it could have been more appropriately translated as 'charla por turnos a través de Internet,' from 'Relay Chat.' In this case, the problem lies in the omission of the second preposition that should be placed between the second and third nouns in Spanish, so that 'Internet Relay Chat' can be perfectly translated as 'charla por turnos mediante/a través de Internet' into Spanish. If the second preposition, 'a través de' or 'mediante,' is not included, the resulting version seems to indicate that Internet is an 'interactive chat' rather than a relay chat that is carried out through the Internet. So, the omission of some of the prepositions that are necessary in Spanish when translating the original English abbreviation can be very confusing.

\subsection{Three-initial abbreviation formed by one adjective and two nouns}

The second most common type of three-initial abbreviations is formed by an adjective or a past participle placed first, followed by two nouns or -ing forms in English. The resulting formula with the two possible versions in Spanish is represented in figure 2:

FIGURE 2

\begin{tabular}{|c|c|}
\hline English & Spanish \\
\hline $\begin{array}{l}\text { adj. }+ \text { noun }(2)+\operatorname{noun}(1) \\
\text { adj. }+ \text { noun }(2)+\text {-ing form }(1) \\
\text { adj. }+ \text {-ing form }+ \text { noun }(1) \\
\text { part. }+ \text { noun }(2)+\operatorname{noun}(1)\end{array}$ & $\begin{array}{c}\text { noun }(1)+\text { prep. }+ \text { noun }(2)+\text { adj. } \\
\text { C }+ \text { B }+ \text { A }\end{array}$ \\
\hline $\mathrm{A}+\mathrm{B}+\mathrm{C}$ & $\begin{array}{c}\text { Noun }(1)+\text { adj. }+ \text { prep. }+ \text { noun }(2) \\
\text { C }+\mathrm{A}+\mathrm{B}\end{array}$ \\
\hline
\end{tabular}

Some examples belonging to this second type of three-initial abbreviations are: 'CGI' (from Common Gateway Interface), 'ADP' (from Automatic Data Processing), 'ACU' (from Automatic Calling Unit), 'EGA' (from Enhanced Graphics Adapter), 'LAN' (from Local Area Network), 'URL' (from Uniform Resource Locator), 'DVD' (from Digital Video Disk), 'LCD’ (from Liquid Crystal Display), etc.

Again we find similar problems when translating this second type of abbreviations into Spanish, i.e. word order and prepositions. In this case, special attention must be paid to word order as we have to decide if the adjective placed first modifies only the immediately following noun or both nouns, appearing in second and third position. In 'LCD' (from Liquid Crystal Display), the adjective 'liquid' affects the 
noun in middle position, and both of them are subordinated to the last noun, so its representative English formula would be $(A+B)+C$. Therefore, the appropriate translation into Spanish for 'LCD' should be 'pantalla de cristal líquido' and not 'pantalla líquida de cristal.' The same can be said of 'LAN' (from Local Area Network), corresponding in Spanish to 'red de área local' and not to 'red local de área.' So, the English and Spanish formulae would be respectively $(\mathrm{A}+\mathrm{B})+\mathrm{C}=\mathrm{C}+(\mathrm{B}+\mathrm{A})$, with the introduction of a preposition between $\mathrm{C}$ and $\mathrm{B}$ in the Spanish version.

However, it sometimes happens that the adjective placed first modifies the other two elements together, i.e., the second and third nouns, and not just the second one. In this case, the connection between all the elements in English can be represented as $\mathrm{A}+(\mathrm{B}+\mathrm{C})$ and the translation into Spanish can be altered since the adjective may be placed in middle or final position. An example of this is 'ADP' (from Automatic Data Processing), where 'Automatic' modifies both nouns, 'Data Processing.' Therefore, the resulting translation into Spanish could be either 'procesamiento de datos automático' or 'procesamiento automático de datos.' In this example, the absence of the plural mark in Spanish clearly indicates that the adjective is directly determined by $\mathrm{C}$ and not by B. Another example is 'GUI' (from Graphical User Interface), corresponding to 'interfaz gráfica de usuario' or 'interfaz de usuario gráfica' in Spanish, but not to 'interfaz de usuario gráfico' as a 'user' cannot be 'graphical.' In this latter case, the adjective has to agree in gender with the third noun, C, and not with the second, B. This could be summarized in the following formula representing the English and the two Spanish versions respectively: $\mathrm{A}+(\mathrm{B}+\mathrm{C})=\mathrm{C}+\mathrm{A}+\mathrm{B}$ or $(\mathrm{C}+\mathrm{B})+\mathrm{A}$, with a preposition placed before B in both Spanish alternatives.

As regards prepositions in Spanish, there is a strong tendency to include 'de' in order to represent all kinds of meaning in English, so 'de' sometimes acts as a default preposition. This tendency is also attested in the general vocabulary, with an increased abuse of certain prepositions, especially 'de,' at the expense of some others such as 'para, por, mediante,' etc. For example, 'PCI' (from 'Peripheral Components Interface) is generally translated as 'interfaz de componentes periféricos' instead of the most appropriate 'interfaz para componentes periféricos', in which 'use, finality' is indicated by means of 'para' and not 'de.' So, the Spanish preposition 'de' is used indiscriminately to denote 'origin, type, object, finality, material, use, etc' and its meaning in the technical and scientific vocabulary often becomes rather vague and ambiguous.

These two types of three-initial abbreviations are the most common ones in English. There are some other types, such as combining two adjectives and a noun, e.g. 'ALU' (from Arithmetic Logic Unit), or putting together two nouns and an adjective or past participle, e.g. 'CAD' (from Computer Aided Design), but these other types cause fewer problems in their translation than the two we previously analyzed.

\section{Four-initial abbreviations}

The two most common types are as follows:

\subsection{Four-initial abbreviations formed by one adjective and three nouns}

The first main type among four-initial abbreviations is formed by an adjective or past participle in initial position, followed by three consecutive nouns. There are two 
possible translations in Spanish of this English structure, as can be seen in the following formula:

FIGURE 3

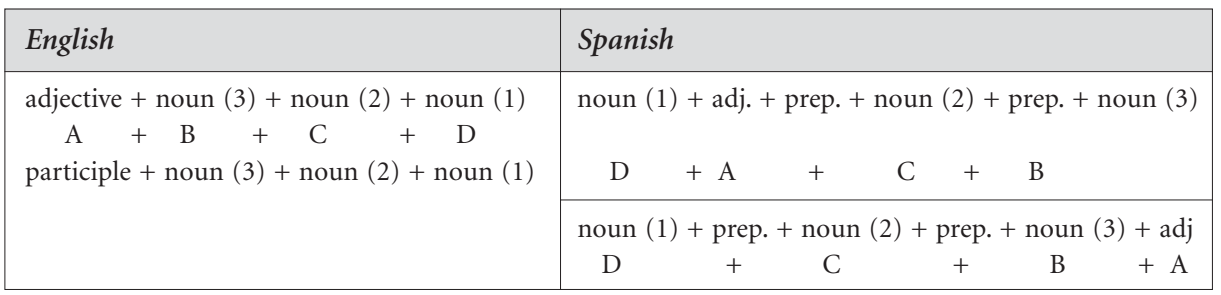

A few examples in English belonging to this type are 'ACIA' (from Asynchronous Communication Interface Adapter), 'BIOS' (from Basic Input Output System), 'DIMM' (from Dual Inline Memory Module), 'SMTP' (from Simple Mail Transfer Protocol), etc. The problem appears once again when we have to decide if the adjective placed first modifies only the immediately following noun or all the rest of the elements. To solve this problem, some knowledge on the original meaning is required. For example, the adjective 'Asynchronous' in the previously mentioned example 'ACIA' affects just the following noun, 'Communication,' but not the last two elements, 'Interface Adapter.' This can be represented through the formula $((\mathrm{A}+\mathrm{B})+\mathrm{C})+\mathrm{D}$, indicating that $\mathrm{A}$, which designates the adjective, affects only $\mathrm{B}$ but not $\mathrm{C}$ or $\mathrm{D}$. So, the translation has to show this kind of syntactic connection between the different elements and word order turns out to be essential if we want to keep close to the original English meaning in our Spanish version. Therefore, 'ACIA' corresponds to 'adaptador para interfaz de comunicaciones asíncronas' and the formula representing this structure in English and Spanish is respectively $((A+B)+C)+D=D+(C+(B+A))$.

However, there is a second option for this type of four-initial abbreviations, where the adjective placed first in the English abbreviation affects all three nouns and not only its immediately following one. This structure is represented by the formula $\mathrm{A}+(\mathrm{B}+\mathrm{C}+\mathrm{D})$. An example of it is 'BIOS' (from Basic Input Output System), where the adjective 'Basic' affects the rest of the elements and, particularly, the last one, the S from 'System.' There are two possibilities for its translation into Spanish depending on whether we place the adjective in second or last position. In both cases, the Spanish adjective has to agree in gender and number with the last noun in English or with the first one in the Spanish version, so that the B from 'Básico' has to agree with the $\mathrm{S}$ from 'Sistema,' i.e. 'sistema básico de entrada y salida,' corresponding to $\mathrm{D}+\mathrm{A}(+\mathrm{B}+\mathrm{C})$, or, alternatively, as 'sistema de entrada y salida básico,' summarized in the formula $\mathrm{D}(+\mathrm{B}+\mathrm{C})+\mathrm{A}$.

The second main problem when translating this type of abbreviation is choosing the appropriate Spanish prepositions that may clarify the connection between the different nouns combined in each structure. As stated before, the most common tendency in Spanish is using 'de' for any kind of meaning and ignoring the rest of the prepositions so that 'VSAM' (from Virtual Storage Access Method) is often translated as 'método de acceso del almacenamiento virtual,' instead of the more suitable 'método de acceso al almacenamiento virtual,' thus clearly indicating 'direction' by means of the preposition 'a'. 


\subsection{Four-initial abbreviations formed by two adjectives and two nouns}

The second main type of four-initial abbreviation in computer terminology includes two consecutive adjectives or past participles in initial position, immediately followed by two consecutive nouns. The formula representing the English structure and its two possible versions in Spanish is as follows:

FIGURE 4

\begin{tabular}{|l|l|}
\hline English & Spanish \\
\hline $\begin{array}{l}\text { adj. (2) + adj. (1) + noun (2) + noun (1) } \\
\text { A + B + C + D }\end{array}$ & $\begin{array}{l}\text { Noun (1) + prep. + noun (2) + adj. (1) + adj (2) } \\
\mathrm{D}+\mathrm{C}+\mathrm{B}+\mathrm{A}\end{array}$ \\
\cline { 2 - 2 } & $\begin{array}{l}\text { Noun (1) + adj. (2) + prep. + noun }(2)+\text { adj. (1) } \\
\mathrm{D}+\mathrm{A}+\mathrm{C}+\mathrm{B}\end{array}$ \\
\hline
\end{tabular}

Among the English abbreviations belonging to this type we may find the following examples: 'ADSL' (from Asymmetrical Digital Subscriber Line), 'ISAM' (from Indexed Sequential Access Method), 'SETT' (from Secure Electronic Transaction Technology), 'SGML' (from Standard Generalized Markup Language), etc. The problem appears when deciding what kind of connection exists between both adjectives and the two nouns. There are two possible translations depending on how we interpret this syntactic relationship.

On the one hand, the first two adjectives may be directly subordinated to the last noun, so both adjectives in Spanish have to agree in gender and number with the noun placed last in the English abbreviation or with the first in the Spanish version. This structure is represented by the following formula: $A+B+((C)+D)=(D+(C))+B+A$. A representative example of it is 'ADSL' (from Asymmetrical Digital Subscriber Line), where both adjectives are directly subordinated to the last noun, 'Line,' so we could reorder this English abbreviation as 'Asymmetrical Digital Line for Subscribers,' but never as 'Asymmetrical Line for Digital Subscribers' or as 'Line for Asymmetrical Digital Subscribers.' A possible Spanish translation for this example can be 'línea asimétrica digital para abonados,' showing this way that both adjectives agree in gender and number with 'line,' not with 'subscriber.'

On the other hand, there is a second possible structure for this type of fourinitial abbreviation, where the first adjective in English is directly subordinated to the last noun and the adjective placed second may just affect the immediately following noun. The formula representing this structure would be $(A+(B+C))+D$, which means that $\mathrm{A}$, on the one hand, depends on $\mathrm{D}$ and $\mathrm{B}$, and on the other, affects just $\mathrm{C}$. This can be seen in examples like 'PISN' (from Private Integrated Services Network), where 'Private' and 'Integrated' are subordinated respectively to 'Network' and 'Services.' In this case, we could reorder the structure in English as a 'Private Network' for 'Integrated Services,' with basically the same meaning as a 'Private Integrated Services Network.' The translation into Spanish has to show this type of connection, i.e. A+D, on the one hand, and $\mathrm{B}+\mathrm{C}$, on the other. So, the gender and number of the Spanish adjectives have to agree with their respective nouns. Therefore, the most suitable translation for 'PISN' in Spanish is 'red privada de servicios integrados,' following the formula $\mathrm{D}+\mathrm{A}+(\mathrm{C}+\mathrm{B})$. 
There are many other types of four-initial abbreviations like those containing four consecutive nouns, e.g. 'MPEG' (from Motion Picture Experts Group), or those combining two nouns and two adjectives in alternate position, e.g. 'ISDN' (from Integrated Services Digital Network). However, the two previous types are the most complex in terms of their translation into Spanish.

\section{Conclusion}

English computer abbreviations are not generally translated into Spanish, which is constantly adopting new contracted forms, e.g. WWW, URL, ISP. But sometimes it is necessary to provide the meaning of these forms, particularly when the abbreviated expression is not very popular or common among computer users. In this case, some translation problems appear. As we have seen, two are the most common types of abbreviations in English computer terminology: three-initial and four-initial abbreviations. There are several combination possibilities within each of these types depending on the grammatical category their elements belong to: nouns, adjectives, verbs, etc. Their structure in English and Spanish is different but the translator has to take into account two main points when trying to translate them.

Firstly, a special care about word order is essential in Spanish as it may determine the accuracy of the final translated version; secondly, an abuse of certain prepositions, particularly 'de,' should be avoided and other alternatives like 'para, por, mediante, etc' are highly recommended if the translator wants to maintain the original meaning of the English abbreviation.

This special care from translators would help to avoid the two most common mistakes when translating computer abbreviations, which are, on the one hand, misinterpreting in Spanish the syntactic connection existing between the different elements combined in the English abbreviation and, on the other, using indiscriminately certain Spanish prepositions to represent all kind of meanings and, therefore, losing a certain amount of specificity.

\section{NOTES}

1. Our analysis of computer abbreviations in this article is based on spelling. So, we exclude here the differences in pronunciation these forms may have in English and Spanish, i.e., if they are pronounced as a series of initials, as a word or as combination of both. Therefore, all comments in this article are made taking into account the written form of the different types of abbreviations and their possible translations into Spanish, leaving aside the phonological perspective and such concepts traditionally linked with it as initialisms, acronyms, etc.

2. Some of these classical elements like 'hyper-,' 'meta-,' 'multi-,' 'mono-,', 'video-' appear often combined with other words and have become very popular in computer terminology: 'hypertext,' 'metafile,' 'multitasking,' 'monouser,' 'videogame,' etc. These new formations were addressed by Adams (1973) and Bauer (1983) as neo-classical compounds.

3. The absence of the plural mark -s in the Spanish version indicates that 'catódico' refers to 'tubo' and not to 'rayos.' Generally, English nouns have a singular form in the abbreviations, even if their meaning is plural, as in 'ISP' (from Internet Service Provider), where 'service' may correspond to 'service' or, more appropriately, to 'services.' But in Spanish, we need to specify if the noun is singular or plural using the plural mark. 


\section{REFERENCES}

Adams, V. (1973): An introduction to Modern English Word-formation, London, Longman.

Aguado De Cea, G. (1993): Diccionario comentado de terminología informática, Madrid, Paraninfo.

Alcaraz, E. (2000): IPA, Inglés Profesional y Académico, Madrid, Alianza Editorial.

BARry, J. (1991): Technobabble, Cambridge, The MIT Press.

Bauer, M. (1983): English Word-Formation, Cambridge, Cambridge University Press.

Bocanegra, A.R. (1990): Acrónimos y otras abreviaturas en informática, Cádiz, Publicaciones de la Universidad de Cádiz.

Cabré, M.T. (1993): La terminología: teoría, metodología, aplicaciones, Barcelona: Antártida.

Cannon, G. (1987): Historical Change and English Word-Formation, Bern, Peter Lang.

Cannon, G. (1989): “Abbreviations and Acronyms in English Word-Formation," American Speech 64:99-127.

Cannon, G. (1993): "Alphabet-based Word-creation." Encyclopedia of Language and Linguistics, Pergamon and Aberdeen University Press.

Collin, S.M.H. (1997): Dictionary of Personal Computing and the Internet, Teddington, Peter Collin.

CVC, Centro Virtual Cervantes, Web Site: <http://www.cvc.es $>$.

Fernández Calvo, R. (1999): Glosario básico inglés-español para usuarios de Internet. Barcelona, Asociación de técnicos de informática, ATI, 2nd ed.

Lang, M.F. (1990): Spanish Word Formation. Productive Derivational Morphology in the Modern Lexis, London, Routledge.

Linder, D. (1999): “Translating Abbreviations from Technical Texts into English.” The American Translators Association Chronicle 9, 53-59.

Rodríguez, F. (1980): Estudio lingüistico de las siglas en el español actual, The University of Alberta, Canada.

Rodríguez, F. (1984): “El género de las siglas.” Revista Española de Lingüística 14, 2, 311-366.

Rodríguez, F. (1987): “Naturaleza sintáctica de las formas siglares. El cambio funcional.” Estudios de Lingüística 4, 139-148. Universidad de Alicante.

Rodríguez, F. (1989): "La derivación de las siglas." Boletín de la Real Academia Española 69, 247, 211-255.

Rodríguez, F. (1990): "La composición de las siglas. La metáfora y otros cambios de sentido." Beiträge zur Romanischen Philologie 29, 1, 105-116.

Rodríguez, F. (1991): “Translation and Borrowing of Acronyms: Main Trends.” International Review of Applied Linguistics 29, 2, 161-170.

Rodríguez, F. (1993): "Las siglas como procedimiento lexicogenésico. Revista Alicante de Estudios Ingleses 9, 9-24. Universidad de Alicante.??

Rodríguez, F. and Cannon, G. (1994): "Remarks on the Origin and Evolution of Abbreviations and Acronyms." English Historical Linguistics. 113, 261-272.

SAger, J.C., Dungeon, D. and McDonald, P. (1980): English Special Languages: principles and practice in science and technology, Wiesbaden, Oscar Brandstetter Verlag.

SAGER, J.C. (1993): Curso práctico sobre el procesamiento de la terminología, Madrid, Fundación Germán Sánchez Ruipérez.

PetrucCi (1989): "Le abbreviazioni nel mondo romano ed il sistema abbreviativo medievale." Breve storia della scritura latina. Roma: Bagatto Libri. 70-73

Telefónica, ed. Ciber-Léxico Comparativo. Retrieved February 2, 1999 from the World Wide Web: $<\mathrm{http}: / /$ www.telefonica.es/fat/elex.html $>$.

VAQUero SÁnchez, A. (1993): Informática: glosario de términos y siglas: diccionario inglés-español, española-inglés, Madrid, McGraw-Hill. 